ERRATUM

http://dx.doi.org/10.1007/s00376-020-2005-3

\title{
Erratum to: LICOM Model Datasets for the CMIP6 Ocean Model Intercomparison Project
}

\author{
Pengfei LIN ${ }^{1,4}$, Zhipeng YU ${ }^{1,4}$, Hailong LIU ${ }^{1,4}$, Yongqiang YU ${ }^{1,4}$, Yiwen LI ${ }^{1,4}$, Jirong JIANG ${ }^{2}$, Wei XUE 3 , \\ Kangjun $\mathrm{CHEN}^{1}$, Qian YANG ${ }^{1,4}$, Bowen ZHAO ${ }^{1,4}$, Jilin WEI ${ }^{1,4}$, Mengrong DING ${ }^{1,4}$, Zhikuo SUN ${ }^{1,4}$, \\ Yaqi WANG ${ }^{1,4}$, Yao MENG ${ }^{1,4}$, Weipeng $\mathrm{ZHENG}^{1,4}$, and Jinfeng MA ${ }^{1}$ \\ ${ }^{1}$ LASG, Institute of Atmospheric Physics, Chinese Academy of Sciences, Beijing 100029, China \\ ${ }^{2}$ Computer Network Information Center, Chinese Academy of Sciences, Beijing 100190, China \\ ${ }^{3}$ Department of Computer Science and Technology, Tsinghua University, Beijing 100084, China \\ ${ }^{4}$ College of Earth and Planetary Sciences, University of Chinese Academy of Sciences, Beijing 100049, China
}

Erratum to: Lin, P. F., and Coauthors, 2020: LICOM model datasets for the CMIP6 Ocean Model Intercomparison Project. Adv. Atmos. Sci., 37(3), 239-249, https://doi.org/10.1007/s00376-019-9208-5.

In the original version of this article, the second author's first name was misspelled as Zhipeng. The correct spelling is Zipeng. The sixth author's first name was misspelled as Jirong. The correct spelling is Jinrong. The correct version is as follows:

\section{LICOM Model Datasets for the CMIP6 Ocean Model Intercomparison Project}

Pengfei LIN ${ }^{1,4}$, Zipeng YU ${ }^{1,4}$, Hailong LIU11,4, Yongqiang YU ${ }^{1,4}$, Yiwen LI ${ }^{1,4}$, Jinrong JIANG², Wei XUE , Kangjun $\mathrm{CHEN}^{1}$, Qian YANG ${ }^{1,4}$, Bowen ZHAO ${ }^{1,4}$, Jilin WEI ${ }^{1,4}$, Mengrong DING ${ }^{1,4}$, Zhikuo SUN ${ }^{1,4}$, Yaqi WANG ${ }^{1,4}$, Yao MENG ${ }^{1,4}$, Weipeng $\mathrm{ZHENG}^{1,4}$, and Jinfeng MA ${ }^{1}$

${ }^{1}$ LASG, Institute of Atmospheric Physics, Chinese Academy of Sciences, Beijing 100029, China

${ }^{2}$ Computer Network Information Center, Chinese Academy of Sciences, Beijing 100190, China

${ }^{3}$ Department of Computer Science and Technology, Tsinghua University, Beijing 100084, China

${ }^{4}$ College of Earth and Planetary Sciences, University of Chinese Academy of Sciences, Beijing 100049, China

In the section "Data availability statement" on page 248 of the original version of this article, the URL of the data should be https://esgf-node.llnl.gov/projects/cmip6.

The online version of this original article can be found at https://doi.org/10.1007/s00376-019-9208-5 